\title{
APARELHOS ENERGETICAMENTE EFICIENTES - UM FOCO NA ILUMINAÇÃO RESIDENCIAL
}

\author{
Energy efficient appliances - A focus on home lighting
}

\author{
Débora Adiane Borges ${ }^{1}$, Antover Panazzolo Sarmento ${ }^{2}$, Gabriel Bernardes de Carvalho ${ }^{3}$
}

Recebido em 12 de setembro de 2016; recebido para revisão em 20 de fevereiro de 2017; aceito em 19 de abril de

2017; disponivel on-line em 16 de maio de 2017.

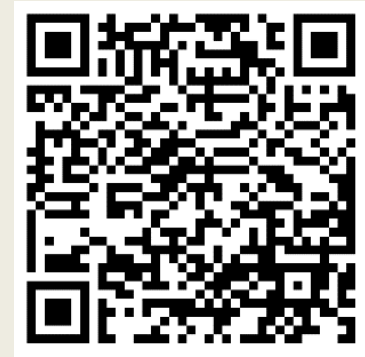

PALAVRAS CHAVE:

Eficiência energética;

Aparelhos

energeticamente

eficientes;

Lâmpadas fluorescentes;

Lâmpadas LED;

Emissão de $\mathrm{CO}_{2}$.

\section{KEYWORDS:}

Energy efficiency;

Energy efficient consumer

electronics;

Fluorescent lamp;

LED lamp;

$\mathrm{CO}_{2}$ emissions.

* Contato com os autores:

${ }^{1}$ e-mail: deboraadiane@gmail.com (D. A. Borges)

Engenheira Civil pela Universidade Federal de Goiás - Regional Catalão, DB Engenharia.

2e-mail: antoverps@gmail.com ( A. P. Sarmento )

Engenheiro Agrícola, Professor Doutor do Curso de Engenharia Civil da Universidade Federal de Goiás, Regional Catalão.

3e-mail: gabrielbdec@gmail.com (G. B. Carvalho)

Graduando em Engenharia Civil na Universidade Federal de Goiás, Regional Catalão. 


\section{INTRODUÇÃO}

A sustentabilidade está diretamente ligada à qualidade de vida atual e das gerações futuras, tornando-se cada vez mais imprescindível. Existem diversas ações que contribuem para a sustentabilidade, entre elas convém destacar os métodos para redução do consumo de energia que fundamentam o princípio de eficiência energética, isto é, uma característica da edificação que representa o seu potencial em possibilitar conforto térmico, visual e acústico aos usuários com baixo custo de energia (Lamberts et al., 2014).

A eficiência energética pode ser alcançada por meio de três métodos: (i) bioclimatologia, (ii) uso de recursos renováveis de energia,(iii) uso de aparelhos energeticamente eficientes. A melhor maneira de reduzir a energia elétrica é através do terceiro método, isto é por meio do uso consciente dos aparelhos e equipamentos (Lamberts; Triana, 2007; Lamberts et al., 2014). Destaca-se que o setor residencial é responsável por grande parte do consumo de energia elétrica do país e está associado principalmente ao aquecimento de água, uso de refrigeradores, geração de conforto dos usuários e iluminação artificial; logo, a redução no consumo dos aparelhos relacionados a essas atividades pode gerar resultados significativos de sustentabilidade (Assis et al., 2007; Oliveira et al., 2015).

O uso consciente dos aparelhos e equipamentos inclui priorizar aqueles que possuem o selo de eficiência energética. Esse selo brasileiro está incluso no Programa Nacional de Conservação de Energia Elétrica (PROCEL Edifica) que certifica materiais e equipamentos e promove o uso eficiente da energia elétrica nas edificações. Incluso nesse programa existe um incentivo para a substituição de lâmpadas por aquelas cada vez mais econômicas e, se outrora, as lâmpadas fluorescentes foram incentivadas, agora, as feitas de LED têm ganhado o mercado (Lamberts; Triana, 2007).

Diante dos grandes desastres ambientais, é necessário que se busquem ações simples que contribuam com a eficiência energética e que todo cidadão possa executar facilmente. A troca de lâmpadas por aquelas mais econômicas é uma dessas ações que pode ser feita por qualquer pessoa, e visto que a iluminação artificial é responsável por um consumo de energia considerável, essa substituição pode ter grande efeito do ponto de vista sustentável. Todavia, convém avaliar se essa troca realmente é viável do ponto de vista ambiental e econômico.

Fiaschi, Bandinelli e Conti (2012) desenvolveram um estudo dessa natureza, eles buscaram maneiras de economizar energia em Certaldo, uma pequena cidade na região da Toscana, na Itália. Os pesquisadores avaliaram que grande parte do consumo de energia era para iluminação das ruas e avaliaram a substituição de lâmpadas de mercúrio por lâmpadas de LED. Concluíram que apesar do investimento inicial relativamente alto, a troca seria viável, tendo baixo tempo de retorno do investimento devido à redução do consumo de energia e de manutenção.

A proposta deste trabalho é fazer uma análise da viabilidade da troca de lâmpadas por lâmpadas mais eficientes focando 0 setor residencial na cidade de Catalão em Goiás.

\section{OBJETIVOS}

Este trabalho teve como objetivo avaliar a eficiência energética obtida na substituição de lâmpadas fluorescentes pelas de LED no interior de uma residência projetada para a cidade de Catalão e verificar a viabilidade dessa troca. Seus objetivos específicos envolveram: realizar uma pesquisa de mercado em Catalão para verificar as principais lâmpadas utilizadas, suas características e o comportamento dos clientes em relação a essa troca; avaliar o preço inicial e ao decorrer dos anos para um projeto com lâmpadas de LED e outro com fluorescentes; calcular a emissão de $\mathrm{CO}_{2}$ na geração de energia para ambos os projetos e quantificar o percentual de redução dos custos e da emissão de $\mathrm{CO}_{2}$ ao final da vida útil das lâmpadas. 


\section{REVISÃO TEÓRICA}

\subsection{USO DE APARELHOS ENERGETICAMENTE EFICIENTES}

O uso de aparelhos energeticamente eficientes é uma das melhores maneiras de se alcançar a eficiência energética no setor residencial. Considerando isso, o Programa Nacional de Conservação de Energia Elétrica (PROCEL Edifica) criou um selo que certifica materiais e equipamentos. Quando eles atendem aos requisitos técnicos necessários, eles recebem uma Etiqueta de Eficiência Energética do Programa Brasileiro de Etiquetagem (PBE). Os produtos que possuem a etiqueta com a letra $A$ são os mais eficientes e assim podem ser classificados em ordem decrescente de eficiência até a letra G. Na Figura 1 está ilustrado um modelo de etiqueta para aparelhos eletrodomésticos e para lâmpadas (Lamberts; Triana, 2007; INMETRO, 2012).

Analisando-se a distribuição do consumo energético no Brasil, é possível perceber que de 2010 a 2014, o setor residencial foi o segundo a consumir mais energia elétrica no país, como mostrado na Tabela 1. Assim, é um setor importantíssimo para instituir medidas de redução no consumo de energia, sem, contudo, afetar o conforto ambiental dos usuários, considerando-se que quando se verifica o consumo de energia dentro do setor residencial, destacam-se o chuveiro, a geladeira e a iluminação, como apresentado na Figura 2.

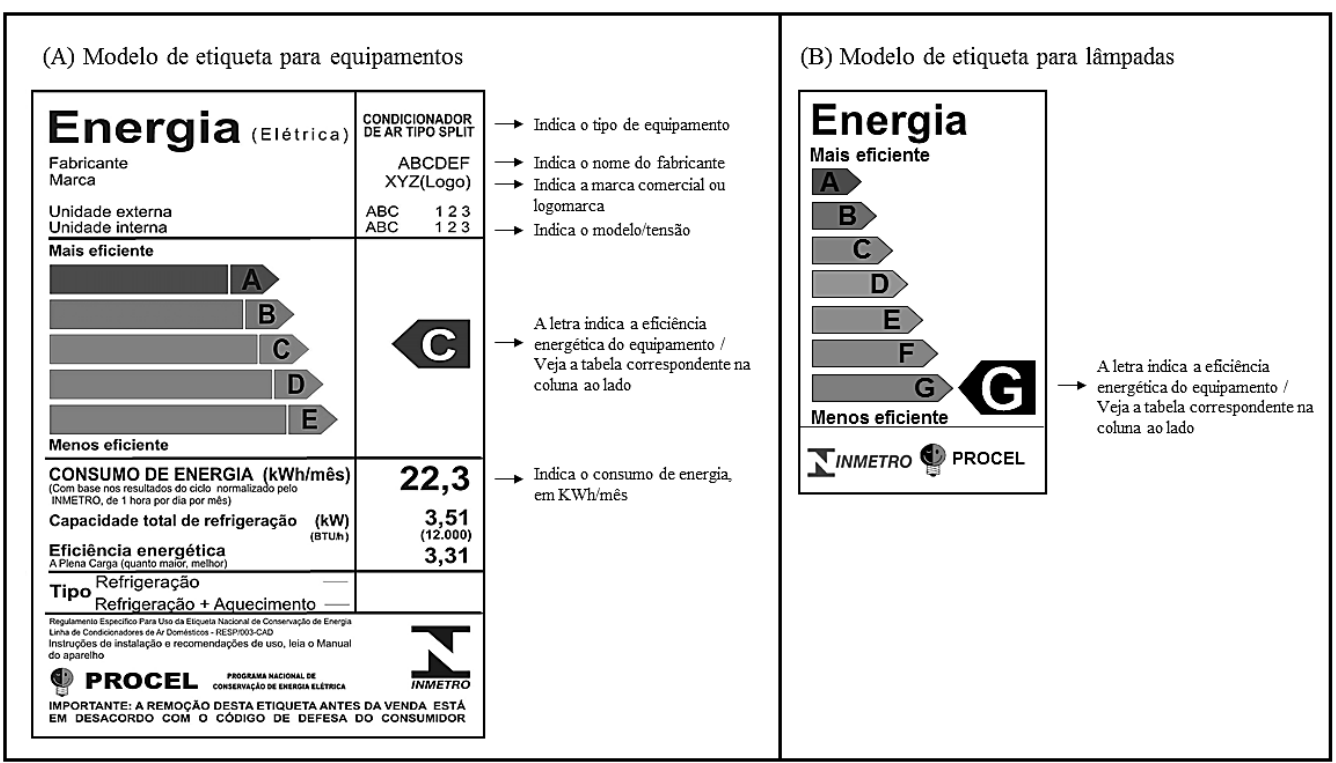

FIGURA 1: Modelo de Etiqueta de Eficiência Energética para equipamentos (A) e para lâmpadas (B). FONTE: INMETRO (2012).

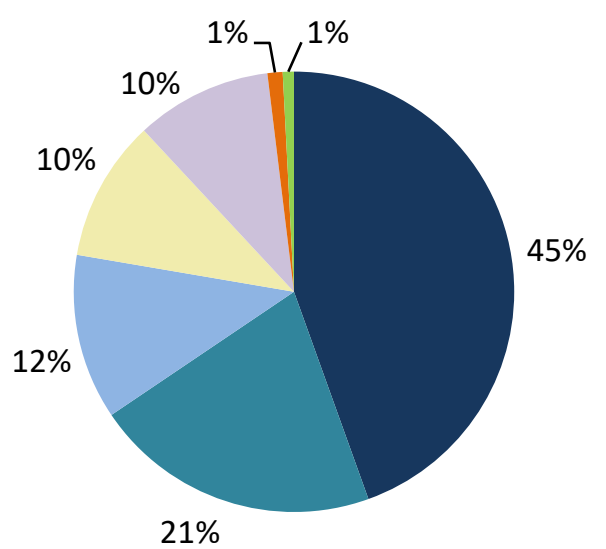

n Chuveiro

- lluminação

Geladeira

Outros

Televisão

Ferro Elétrico

- Máquina de Lavar

FIGURA 2: Estimativa de consumo por eletrodomésticos de acordo com uso hipotético de uma residência com consumo mensal médio de $220 \mathrm{kWh} / \mathrm{mês}$.

FONTE: Companhia Paranaense de Energia (COPEL, 2011). 
TABELA 1: Consumo de energia por classe no Brasil (GWh).

\begin{tabular}{c|c|c|c|c|c|c} 
& $\mathbf{2 0 1 0}$ & $\mathbf{2 0 1 1}$ & $\mathbf{2 0 1 2}$ & $\mathbf{2 0 1 3}$ & $\mathbf{2 0 1 4}$ & Part. \% (2014) \\
\hline Brasil & 415.667 & 433.015 & 448.177 & 463.134 & 475.432 & 100,0 \\
\hline Residencial & 107.215 & 111.971 & 117.646 & 124.908 & 132.399 & 27,8 \\
\hline Industrial & 179.478 & 183.576 & 183.475 & 184.685 & 179.618 & 37,8 \\
\hline Comercial & 69.170 & 73.482 & 79.226 & 83.704 & 89.840 & 18,9 \\
\hline Rural & 18.906 & 21.027 & 22.952 & 23.455 & 25.671 & 5,4 \\
\hline Poder público & 12.817 & 13.222 & 14.077 & 14.653 & 15.354 & 3,2 \\
\hline Iluminação pública & 12.051 & 12.478 & 12.916 & 13.512 & 14.043 & 3,0 \\
\hline Serviço público & 13.589 & 13.983 & 14.525 & 14.847 & 15.242 & 3,2 \\
\hline Próprio & 2.441 & 3.277 & 3.360 & 3.371 & 3.265 & 0,7 \\
\hline
\end{tabular}

A sustentabilidade dos chuveiros pode ser melhorada através da implantação de aquecimento solar. Para equipamentos como geladeira, máquina de lavar, televisão, ferro elétrico e outros eletrodomésticos pode-se buscar a redução no consumo de energia escolhendo aqueles com etiqueta do PROCEL o mais próximo possível do nível $A$, além de outras medidas de conscientização do usuário.

Nota-se, porém, que mais que $21 \%$ do consumo residencial é pela iluminação e em termos mundiais, Uddin, Shareef e Mohamed (2013) citam que esse consumo é de $20 \%$. Logo, medidas de redução no consumo de lâmpadas são imprescindíveis, tal que se pode observar a busca frequente dos governos e fabricantes em produzir lâmpadas cada vez mais eficientes. Inserido nos Programas do PROCEL há um incentivo para a substituição de lâmpadas por aquelas cada vez mais econômicas e verifica-se que após a troca intensiva das lâmpadas incandescente pelas fluorescentes, outra opção que vem ganhando mercado nos últimos anos são as lâmpadas de LED (Lamberts; Dutra; Pereira, 2014).

\subsection{LÂMPADAS LED}

A adoção de lâmpadas de LED é um bom método para aumentar a eficiência da iluminação em uma residência e contribuir para a redução do consumo de energia (Leelakulthanit, 2014). Os LEDs (Light Emitting Diodes - Diodos Emissores de Luz) são semicondutores do estado sólido de iluminação. Esse estado é definido como aquele em que a luz é emitida a partir de um objeto sólido (no caso os LEDs) convertendo a energia elétrica diretamente em luz, ao invés de usar descargas ou filamentos, como nas lâmpadas fluorescentes e incandescentes, respectivamente (Philips, 2010; Ferreira, 2014).

Em relação às várias qualidades das lâmpadas de LED pode-se citar que, geralmente, elas não queimam repentinamente, como acontece com as lâmpadas incandescentes, em vez disso, elas vão se tornando mais fracas ao longo do tempo. Elas também não emitem raio ultravioleta nem luz infravermelha, produzem pouquíssimo calor, são resistentes a choques e vibrações, operam de forma eficaz em ambientes frios, possuem altíssima vida útil, consumo baixo de energia, tamanho reduzido, variedade de cores, luz dirigida e alta eficiência energética (Leelakulthanit, 2014; Lamberts; Dutra; Pereira, 2014).

Além de todos esses benefícios é importante destacar que as lâmpadas de LED causam uma redução considerável nos impactos ambientais. Para começar, elas não possuem mercúrio $(\mathrm{Hg}$ ) ou outros metais pesados, como as fluorescentes, e assim eliminam as chances de criar a poluição quando os bulbos são eliminados no final do seu ciclo de vida (Leelakulthanit, 2014). Considerando a redução no consumo de energia, elas também contribuem para uma queda importante nas emissões de $\mathrm{CO}_{2}$, e consequentemente para a redução do efeito estufa, um fator importante para avaliar a sustentabilidade (Ferreira, 2014).

Entende-se, portanto, que adotar 
lâmpadas de tecnologia LED é um método eficaz para reduzir o consumo de eletricidade. No entanto, para avaliar o verdadeiro impacto ambiental de qualquer tecnologia de iluminação, é necessário verificar os materiais e recursos energéticos utilizados ao longo de todo o ciclo de vida da lâmpada, diagnóstico conhecido como Análise do Ciclo de Vida - ACV (Life-Cycle Assessment (LCA)). Mesmo que a energia consumida durante a fase de uso por lâmpadas de LED seja inferior à consumida por lâmpadas fluorescentes e incandescentes, ainda é importante saber se a energia e os benefícios ambientais durante as fases iniciais e finais do processo do ciclo de vida continuam compensando a tecnologia. Por isso, o Departamento de Energia dos EUA (U.S. DEPARTMENT OF ENERGY (DOE)) e o Programa de Iluminação de Estado Sólido (SolidState Lighting (SSL) Program) reconheceram a importância de compreender o ciclo de vida antes de incentivar a adoção em massa de produtos de LED e desenvolveram um estudo verificando todas as suas etapas (DOE, 2012a).

O estudo do DOE utilizou como unidade básica, para comparativos, a quantidade de luz ou energia luminosa, que representa a quantidade de luz emitida por uma lâmpada durante sua vida, dada pelo produto do fluxo luminoso $(\phi)$, dado em lúmens $(\mathrm{Im})$, pela vida útil de uma lâmpada. Com base nas lâmpadas locais e eficácia das mesmas no ano de 2011, o estudo chegou a conclusão de que eram necessárias 22 lâmpadas incandescentes ou 3 fluorescentes para gerar a mesma energia luminosa de 1 lâmpada LED (equivalente a 20 milhões de Imhora). Na Figura 3 está apresentado esse resultado com as propriedades em evidência.

A primeira parte do estudo concluiu que $o$ consumo de energia do ciclo de vida, ao considerar somente as fases de fabricação, transporte e uso, de lâmpadas LED e de lâmpadas fluorescentes compactas era semelhante até o ano de 2011. Os autores concluíram que a fase de utilização é a que mais contribui para o consumo de energia. Verificaram, também, que a etapa de produção é constituída de elevado percentual de incertezas. 0 estudo ainda mostrou que segundo as evoluções previstas para a produção das lâmpadas de LED, provavelmente essa eficiência aumentaria tornando as lâmpadas de LED muito mais eficientes (DOE, 2012a).
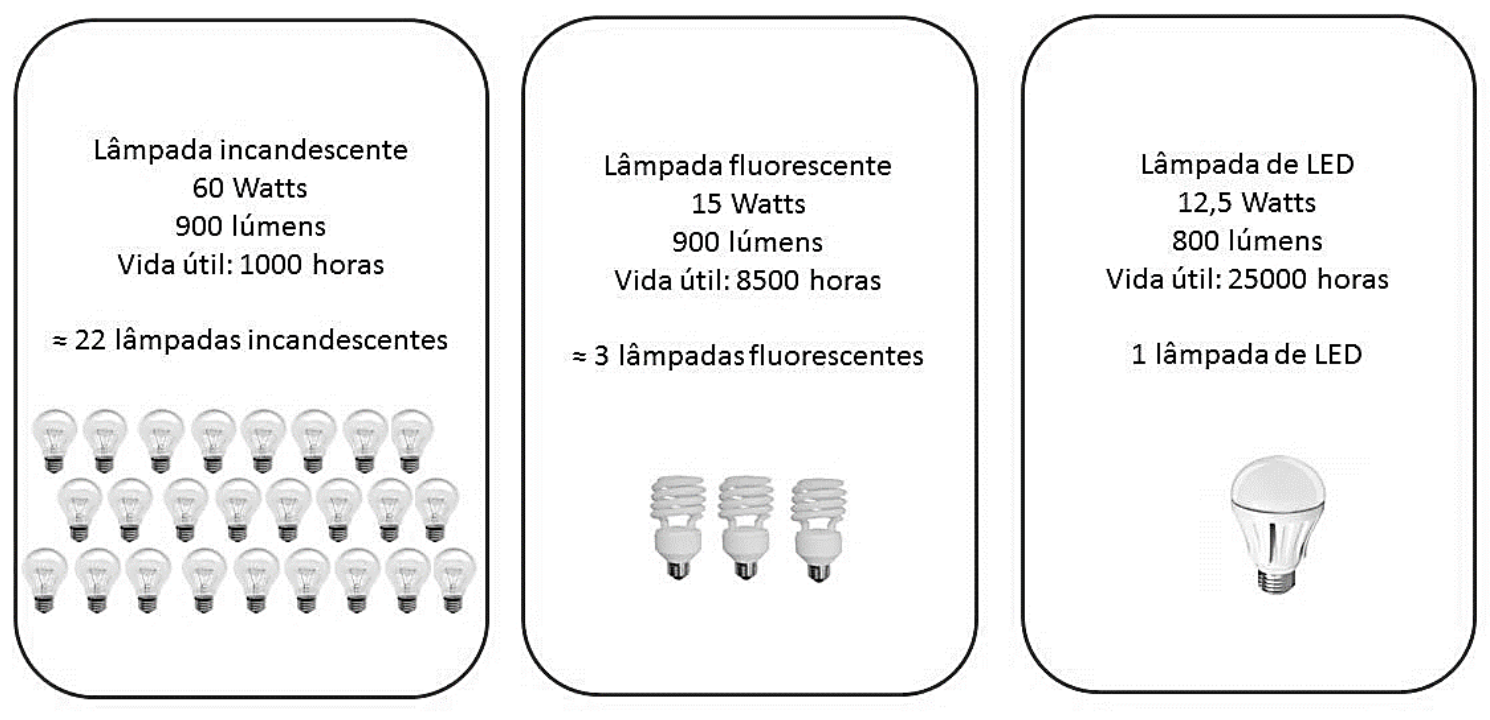

FIGURA 2: Número de lâmpadas necessárias para fornecer 20 milhões de lúmens-hora. FONTE: Traduzido e adaptado de DOE (2012). 
A segunda parte do estudo envolveu mais etapas do ciclo de vida (matéria-prima, produção, transporte, uso e disposição final). Nesta etapa as lâmpadas de LED se mostraram mais eficientes após uma análise de vários tipos de impactos ambientais. Levando em consideração a emissão de $\mathrm{CO}_{2}$, que serve como um dos parâmetros de sustentabilidade, o estudo mostrou que em 2012, as lâmpadas incandescentes tinham o maior impacto ambiental para o aquecimento global com uma média de $51 \mathrm{~kg}$ de $\mathrm{CO}_{2}$ equivalente por milhão de lúmens-hora $(\mathrm{kg}$ $\mathrm{CO}_{2}$ eq $\left.\left(10^{6} \mathrm{Imh}\right)^{-1}\right)$ e um desvio padrão de 3,5 , as lâmpadas fluorescentes tinham uma média de 15,2 $\mathrm{kg} \mathrm{CO}$ eq $\left(10^{6} \mathrm{Imh}\right)^{-1}$ com um desvio padrão de $1,4 \mathrm{e}$ as lâmpadas LED tinham uma média de $12,5 \mathrm{~kg}$ $\mathrm{CO}_{2}$ eq $\left(10^{6} \mathrm{Imh}\right)^{-1}$ com o mesmo desvio padrão das lâmpadas fluorescentes. Finalmente, considerando as evoluções previstas na produção de LED, previuse para 2017 que a lâmpada terá uma média de 5,7 $\mathrm{kg} \mathrm{CO}_{2}$ eq $\left(10^{6} \mathrm{Imh}\right)^{-1} \mathrm{com}$ um desvio padrão de 0,6 (DOE, 2012b).

O estudo do DOE (2012b) indicou que a fase de uso é a mais relevante. Baseando-se nesse estudo, o presente trabalho se concentrou em avaliar a etapa de uso das lâmpadas fluorescentes e de LED para uma casa-piloto projetada para Catalão, avaliando a emissão de $\mathrm{CO}_{2}$ e a viabilidade econômica dessa troca. O estudo não incluiu lâmpadas incandescentes, visto que a maioria das mesmas já está proibida no Brasil. O processo de proibição iniciou-se em 2010, regulamentado pela Portaria Interministerial № 1.007, de 31 de dezembro de 2010 e visa a proibição da fabricação e importação de todos os tipos incandescentes até o ano de 2016 e se prevê que deixarão completamente o mercado em 2017.

\subsection{MÉTODO DE LUMENS}

O Método dos Lumens é recomendado pela IESNA (IIluminating Engineering Society of North America - Sociedade de Engenharia da Iluminação Norte Americana) e é um meio prático e rápido de se calcular uma configuração de luminárias que atenda aos requisitos de um projeto de iluminação (Santos, 2010; Toledo, 2008). Entende-se que esse método tem por objetivo estabelecer o número de luminárias necessárias para atender a um iluminamento médio especificado, conforme as dimensões do ambiente e atividades a serem desenvolvidas nele, com base nos valores fornecidos na NBR 5413 (ABNT, 1992).

Dois conceitos são imprescindíveis para uma melhor compreensão desse método: fluxo luminoso e iluminância. O fluxo luminoso é a potência de luz total emitida por uma fonte luminosa, ou seja, é a luz total que incide sobre uma superfície, cuja unidade é lumens (Im). O iluminamento ou iluminância é a densidade do fluxo luminoso em uma superfície sendo iluminada, dado pela razão do fluxo luminoso que incide em uma superfície e a área da mesma, tendo como unidade Lux (Ix ou $\mathrm{Im} / \mathrm{m}^{2}$ ); de modo prático, entende-se como o nível de iluminação ou a quantidade de luz em um ambiente, que pode ser medida com um luxímetro. Destaca-se que como a distribuição desse fluxo luminoso ou dessa quantidade de luz não é uniforme em todos os pontos, utiliza-se comumente o iluminamento médio ou iluminância média (Creder, 2007; Philips, 2010).

De forma geral, o método dos lúmens pode ser resumido nos seguintes passos (Creder, 2007; Freitas, 2009; Kawasaki, 2012):

(1) Estabelecer o iluminamento médio do local (E), considerando que na NBR 5413 (ABNT, 1992) estão os valores para iluminância previstos para cada tipo de local ou atividade.

(2) Estabelecer o tipo de lâmpada e de luminária a serem utilizadas no local, identificando o seu fluxo luminoso. Várias literaturas e softwares contêm tabelas com os tipos de luminárias e suas especificações.

(3) Cálculo do índice do local que leva em conta as dimensões do local e a quantidade de luz refletida por paredes e teto por meio da Equação 1.

$$
\mathrm{K}=\frac{\mathrm{C} \times \mathrm{L}}{\mathrm{H} \times(\mathrm{C}+\mathrm{L})}
$$

Em que:

C = comprimento do local, considerando formato retangular $(\mathrm{m})$;

$\mathbf{L}=$ largura do local $(\mathrm{m})$;

$\mathbf{H}=$ altura de montagem das luminárias $(\mathrm{m})$. 
(4) Determinação do Fator de Utilização $\left(F_{u}\right)$ a partir de tabelas de recinto fornecidas por fabricantes de luminárias, onde basta cruzar o valor do índice do Local $\mathrm{K}$ com os dados de fração de luz refletida por pisos, paredes e teto como apresentado na Tabela 2.

(5) Determinação do Fator de Depreciação $\left(F_{d}\right)$ ou de manutenção. Este coeficiente, menor ou igual a 1, representa uma ponderação que leva em conta a perda de eficiência luminosa das luminárias devido à contaminação do ambiente. Existem tabelas que fornecem valores deste coeficiente em função do grau de contaminação do local e da frequência de manutenção (limpeza) das luminárias como apresentado na Tabela 3.

(6) Determinação do fluxo luminoso total $\varphi$ (em lúmen) que as luminárias deverão produzir, de acordo com a Equação 2:

$$
\varphi=\frac{\mathrm{E} \times \mathrm{S}}{F_{u} \times F_{d}}
$$

Em que:

$\mathbf{E}=$ iluminamento médio (lux);

$\mathbf{S}=\mathrm{C} \times \mathrm{L}$ - área do local $\left(\mathrm{m}^{2}\right)$;

$\mathbf{F}_{\mathbf{u}}=$ Fator de Utilização;

$\mathbf{F}_{\mathrm{d}}=$ Fator de Depreciação.

* Determinação do número de luminárias $\mathrm{N}_{\mathrm{L}}$ conforme a Equação 3:

$$
N_{L}=\frac{\varphi}{\varphi_{L}}
$$

Em que:

$\varphi=$ fluxo luminoso total (Im);

$\varphi_{\mathbf{L}}=$ fluxo luminoso $(\mathrm{Im})$ de uma luminária.

(7) Distribuição do número de luminárias de forma a produzir um arranjo uniformemente distribuído. Uma vez ajustado o número efetivo de iluminarias por linha e coluna, efetua-se o cálculo da iluminância efetiva no plano de trabalho.

\begin{tabular}{c|c|c}
\hline \multicolumn{3}{c}{ TABELA 2 - Índices de reflexão. } \\
\hline Índice & Reflexão & Significado \\
\hline 1 & $10 \%$ & Superfície escura \\
\hline 3 & $30 \%$ & Superfície média \\
\hline 5 & $50 \%$ & Superfície clara \\
\hline 8 & $80 \%$ & Superfície Branca \\
\hline
\end{tabular}

TABELA 3 - Fator de depreciação ou fator de manutenção.

\begin{tabular}{c|c|c|c} 
Tipo de ambiente & \multicolumn{3}{|c}{ Período de manutenção (h) } \\
\cline { 2 - 5 } & $\mathbf{2 5 0 0}$ & $\mathbf{5 0 0 0}$ & $\mathbf{7 5 0 0}$ \\
\hline Limpo & 0,95 & 0,91 & 0,88 \\
\hline Normal & 0,91 & 0,85 & 0,8 \\
\hline Sujo & 0,8 & 0,66 & 0,57 \\
\hline
\end{tabular}




\section{MATERIAL E MÉTODOS}

A pesquisa foi constituída de três etapas para avaliação da eficiência energética adquirida através da substituição das lâmpadas fluorescentes pelas de LED na cidade de Catalão. A primeira consistiu em uma pesquisa de mercado nas lojas do setor elétrico da cidade de Catalão para saber quais as principais lâmpadas utilizadas, suas características e o comportamento dos clientes em relação a essa troca. Buscaram-se todas as lojas de materiais elétricos na lista telefônica da cidade ( 6 lojas) e, a partir das encontradas, realizou-se a pesquisa, composta por seis perguntas:

(1 e 2) Vocês ainda vendem lâmpadas incandescentes? Quais as principais vendidas para classe média?

(3) Quais as lâmpadas fluorescentes mais vendidas para residências de padrão classe média?

(4) Quais as lâmpadas de LED mais vendidas para residências de padrão classe média e que substitui bem as fluorescentes?

(5 e 6) Como está o processo de troca das lâmpadas convencionais pelas lâmpadas de LED? Qual tem sido a perspectiva e comportamento do cliente diante da mudança?

Sabendo as lâmpadas fluorescentes e LED mais vendidas no mercado catalano, elaboraram-se dois projetos luminotécnicos para o interior de um modelo de casa padrão, apresentado na Figura 4, escolhido com base em outra pesquisa (BORGES, 2016), que auxiliou na elaboração de um projetopiloto que agradaria a maioria dos clientes da cidade de Catalão. O primeiro foi feito com lâmpadas fluorescentes e o segundo com lâmpadas de LED utilizando como base o método dos lúmens. Para isso, utilizou-se do auxílio do software Lumine V4 (versão demonstrativa), da AutoQi para os cálculos do método dos lúmens, uma vez que o mesmo possui um cadastro de luminárias e lâmpadas bastante amplo, além da possibilidade de acrescentar novos modelos e um guia rápido que facilita sua utilização. E para a parte gráfica utilizouse o AutoCad (versão estudantil), baseado nos resultados do Lumine V4 (AUTOQI, 2015; AUTODESK, 2015).

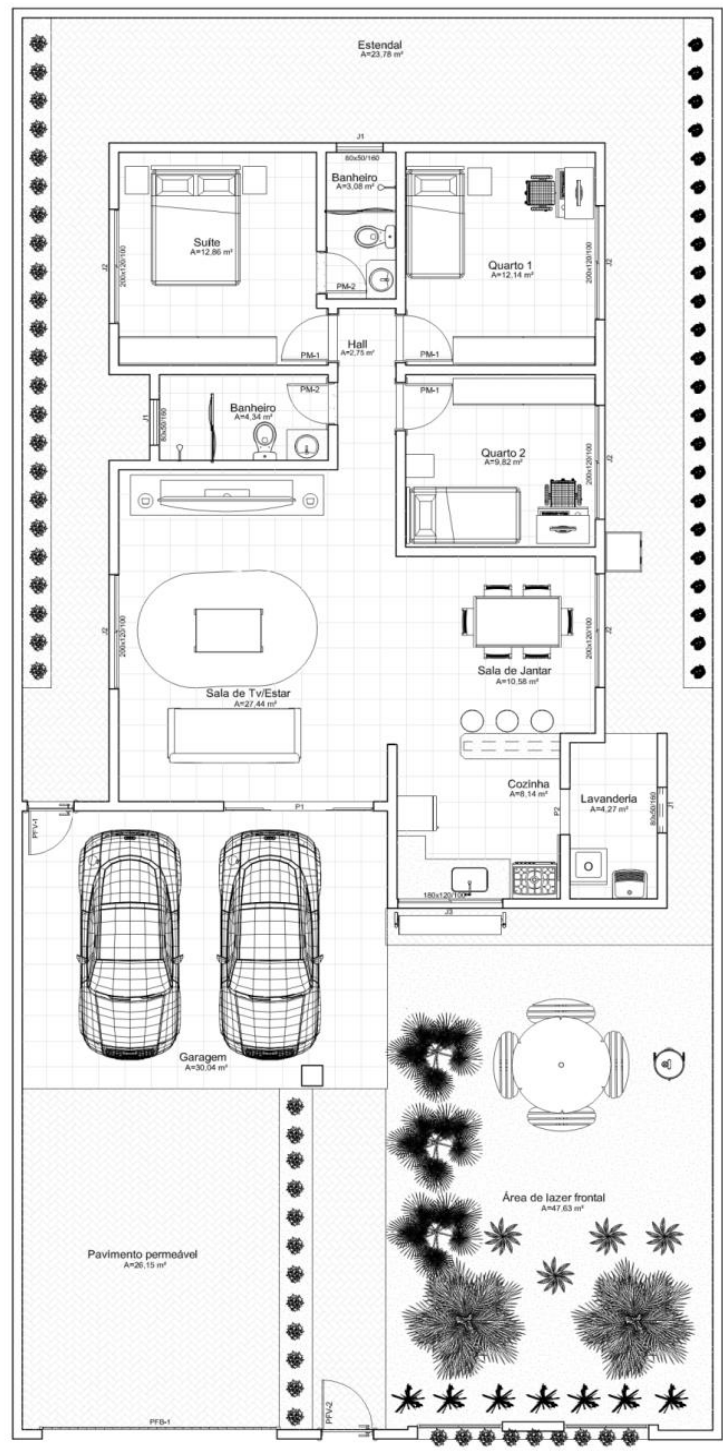

FIGURA 3: Planta Baixa Padrão para a cidade de Catalão. FONTE: Autoria Própria (2016).

O software Lumine V4 efetua o cálculo da quantidade de lâmpadas necessárias e uma configuração adequada pelo método dos lúmens. Para o cálculo, considerou-se o valor médio e geral das iluminâncias da NBR 5413 (ABNT, 1992) para cada cômodo, conforme o Quadro 1.

QUADRO 1: Valores de iluminâncias utilizados para cada cômodo da casa-piloto para a cidade de Catalão.

Salas de estar, cozinhas, quartos de dormir e banheiros Hall, escadas, despensas, garagens 150 100 
Considerou-se que a casa possui predominantemente cores claras para maior eficiência energética, tal que se utilizou o teto branco, a parede clara e o piso médio, resultando nos índices de reflexão iguais a 80\%, 50\% e 30\%, respectivamente. Em relação ao fator de manutenção, utilizou-se esse fator sendo igual a 0,85 , equivalente a um ambiente normal e período de manutenção médio de 5000 horas. Com base nessas informações e na seleção do perímetro dos cômodos, o software Lumine V4 auxiliou na distribuição adequada das luminárias obedecendo criteriosamente o método dos lúmens. Ressalta-se que o projeto luminotécnico não foi feito para áreas externas como corredores e jardins, por levar em consideração nessa etapa o método dos lúmens e a NBR 5413 (ABNT, 1992), que são recomendados para iluminação de interiores.

A última parte foi composta pela elaboração de tabelas que fizeram o comparativo dos custos e benefícios para a casa projetada nos dois modelos. Nessa etapa, avaliou-se o valor gasto para aquisição das lâmpadas e para o consumo de energia e o impacto ambiental quantificado pela emissão de $\mathrm{CO}_{2}$ verificando as reduções e o tempo para retorno financeiro após a troca das lâmpadas fluorescentes pelas de LED.

\section{RESULTADOS E DISCUSSÃO}

$\mathrm{Na}$ pesquisa realizada nas lojas de materiais elétricos de Catalão, a primeira pergunta consistia em saber se lâmpadas incandescentes ainda são vendidas nessas lojas e, se sim, quais as mais vendidas. Mediante a proibição da maior parte dessas lâmpadas detectou-se que $50 \%$ das lojas não vendem mais nenhum tipo de lâmpada incandescente e os outros $50 \%$ vendem lâmpadas de $40 \mathrm{~W}$, mas somente até acabarem no estoque.

A segunda pergunta era voltada para as principais lâmpadas fluorescentes vendidas para residências de classe média. Verificou-se que a preferência do cliente catalano é para lâmpadas compactas de 15 e $20 \mathrm{~W}$ que representaram $78 \%$ das respostas. Houve apenas duas respostas diferentes, uma apontou a lâmpada compacta de 32 W e a outra a tubular de $40 \mathrm{~W}$ como a mais utilizada por aqueles que necessitam ou preferem as tubulares, mas prevaleceram as de 15 e $20 \mathrm{~W}$ cujas características são apresentadas na Tabela 4.

Quando perguntado acerca dos produtos de LED, não foi observado um produto padrão em todas as lojas; porém, todas as lâmpadas citadas na pesquisa estão na faixa de potência entre 5 e $15 \mathrm{~W}$, como mostrado na Tabela 5; e a lâmpada citada pela maioria como a mais acessível é a do tipo Pera High Power LED da Avant de $7 \mathrm{~W}$. A mais diferenciada é a Ultra LED AR111 da Golden com a aplicação de luz dirigida, usada mais para decoração e iluminação de pontos específicos e jardins.

Acerca do processo de troca das lâmpadas convencionais incandescentes e fluorescentes pelas de LED, nas lojas foi relatado que o processo é lento e que as fluorescentes ainda são as mais pedidas. Acreditam, todavia, que há uma tendência da substituição mais intensiva pelas lâmpadas de LED, porque estão sendo encontradas em preços mais acessíveis e uma grande parte dos clientes está substituindo gradualmente todas as suas lâmpadas que queimam pelas de LED.

TABELA 4: Principais lâmpadas fluorescentes vendidas em Catalão.

\begin{tabular}{c|c|c|c|c|c|c|c|c} 
Lâmpada & $\begin{array}{c}\text { Marcas mais } \\
\text { vendidas }\end{array}$ & $\begin{array}{c}\text { Áreas de } \\
\text { aplicação }\end{array}$ & $\begin{array}{c}\text { Vida útil } \\
\text { média (h) }\end{array}$ & $\begin{array}{c}\text { Potência } \\
\text { nominal } \\
\text { (W) }\end{array}$ & $\begin{array}{c}\text { Fluxo } \\
\text { luminoso } \\
\text { médio (Im) }\end{array}$ & $\begin{array}{c}\text { Eficiência } \\
\text { energética } \\
\text { (Im/W) }\end{array}$ & $\begin{array}{c}\text { Classificação } \\
\text { Energética } \\
\text { (PROCEL) }\end{array}$ & $\begin{array}{c}\text { Preço } \\
\text { Médio } \\
\text { (R\$) }\end{array}$ \\
\hline $\begin{array}{c}\text { Fluorescente } \\
15 \text { W }\end{array}$ & $\begin{array}{c}\text { Osram/ } \\
\text { Philips/ Avant }\end{array}$ & Uso Geral & 6000 & 15 & 815,0 & 54,4 & $\mathrm{~A}$ & 8,15 \\
\hline $\begin{array}{c}\text { Fluorescente } \\
20 \mathrm{~W}\end{array}$ & Avant/ Philips & Uso Geral & 6000 & 20 & 1200,0 & 60,0 & $\mathrm{~A}$ & 11,50 \\
\hline
\end{tabular}


TABELA 5: Principais lâmpadas de LED vendidas em Catalão.

\begin{tabular}{c|c|c|c|c|c|c|c|c|c}
\hline Lâmpada & $\begin{array}{c}\text { Marcas } \\
\text { mais } \\
\text { vendidas }\end{array}$ & $\begin{array}{c}\text { Áreas de } \\
\text { aplicação }\end{array}$ & $\begin{array}{c}\text { Vida útil } \\
\text { média } \\
\text { (h) }\end{array}$ & $\begin{array}{c}\text { Potência } \\
\text { nominal } \\
\text { (W) }\end{array}$ & $\begin{array}{c}\text { Fluxo } \\
\text { luminoso } \\
\text { médio (Im) }\end{array}$ & $\begin{array}{c}\text { Eficiência } \\
\text { energética } \\
\text { (Im/W) }\end{array}$ & $\begin{array}{c}\text { Soque } \\
\text { te } \\
\text { (Base) }\end{array}$ & $\begin{array}{c}\text { Classificação } \\
\text { Energética } \\
\text { (PROCEL) }\end{array}$ & $\begin{array}{c}\text { Preço } \\
\text { Médio } \\
\text { (R\$) }\end{array}$ \\
\hline $\begin{array}{c}\text { Pera High } \\
\text { Power LED }\end{array}$ & Avant & Uso Geral & 25000 & 7 & 600 & 86 & E 27 & A & 22,50 \\
\hline $\begin{array}{c}\text { Pera 12 W } \\
\text { Bivolt }\end{array}$ & Avant & Uso Geral & 25000 & 12 & 1.000 & 83 & E27 & A & 37,00 \\
\hline $\begin{array}{c}\text { Prime LED } \\
\text { A60 TKL 900 }\end{array}$ & Taschibra & Uso Geral & 25000 & 9 & 900 & 100 & E27 & A & 22,00 \\
\hline $\begin{array}{c}\text { Ultra LED } \\
\text { AR111 }\end{array}$ & Golden & $\begin{array}{l}\text { Luz } \\
\text { dirigida }\end{array}$ & 25000 & 14 & - & - & GU10 & 102,50 \\
\hline Eco LED A60 & FLC Led & Uso Geral & 30000 & 10 & 806 & 81 & E27 & A & 20,75 \\
\hline
\end{tabular}

Diante dos resultados encontrados, optou-se pela realização do primeiro projeto luminotécnico com o uso das lâmpadas fluorescentes compactas de 15 e $20 \mathrm{~W}$ e para o segundo, das lâmpadas de Pera High Power LED de $7 \mathrm{~W}$ e Pera LED de $12 \mathrm{~W}$.

Considerando a energia luminosa, tendo o valor de 15 milhões de luméns-hora como base, percebe-se que é necessária 1 lâmpada de LED de 7 W contra 0,6 de LED de 12 W, 3 fluorescentes de 15 W ou 2 fluorescentes de $20 \mathrm{~W}$ para fornecer a mesma quantidade de luz ao decorrer da sua vida útil, como representado na Figura 5. A lâmpada de LED de $7 \mathrm{~W}$ e a de $12 \mathrm{~W}$ teriam o mesmo custobenefício no mercado catalano, pois ao tempo que uma lâmpada de $7 \mathrm{~W}$ geraria 15 milhões de lúmenshora custando $\mathrm{R} \$ \mathbf{2 2 , 5 0}$, a de $12 \mathrm{~W}$, até gerar os mesmos 15 milhões, estaria em $60 \%$ da sua vida útil, tendo o mesmo valor final. Em compensação, 3 lâmpadas fluorescentes de $15 \mathrm{~W}$ ou 2 de $20 \mathrm{~W}$ custariam $\mathrm{R} \$ 24,45$ e $\mathrm{R} \$ 23,00$, respectivamente, comprovando através da simples análise da quantidade de luz que o custo das lâmpadas de LED é inferior a longo prazo, garantindo maior economia e desmistificando o senso comum de que as lâmpadas de LED são mais caras.

Nas Figuras 6 e 7 são apresentadas as Plantas Baixas da casa-piloto de Catalão com os pontos de iluminação e suas indicações para lâmpadas fluorescentes e de LED, respectivamente. Ressalta-se que na escolha do arranjo adequado para cada cômodo, buscou-se priorizar aspectos que usassem um número menor de lâmpadas e luminárias, tal que no projeto com as lâmpadas de LED, as de $12 \mathrm{~W}$ prevaleceram sobre as de $7 \mathrm{~W}$.
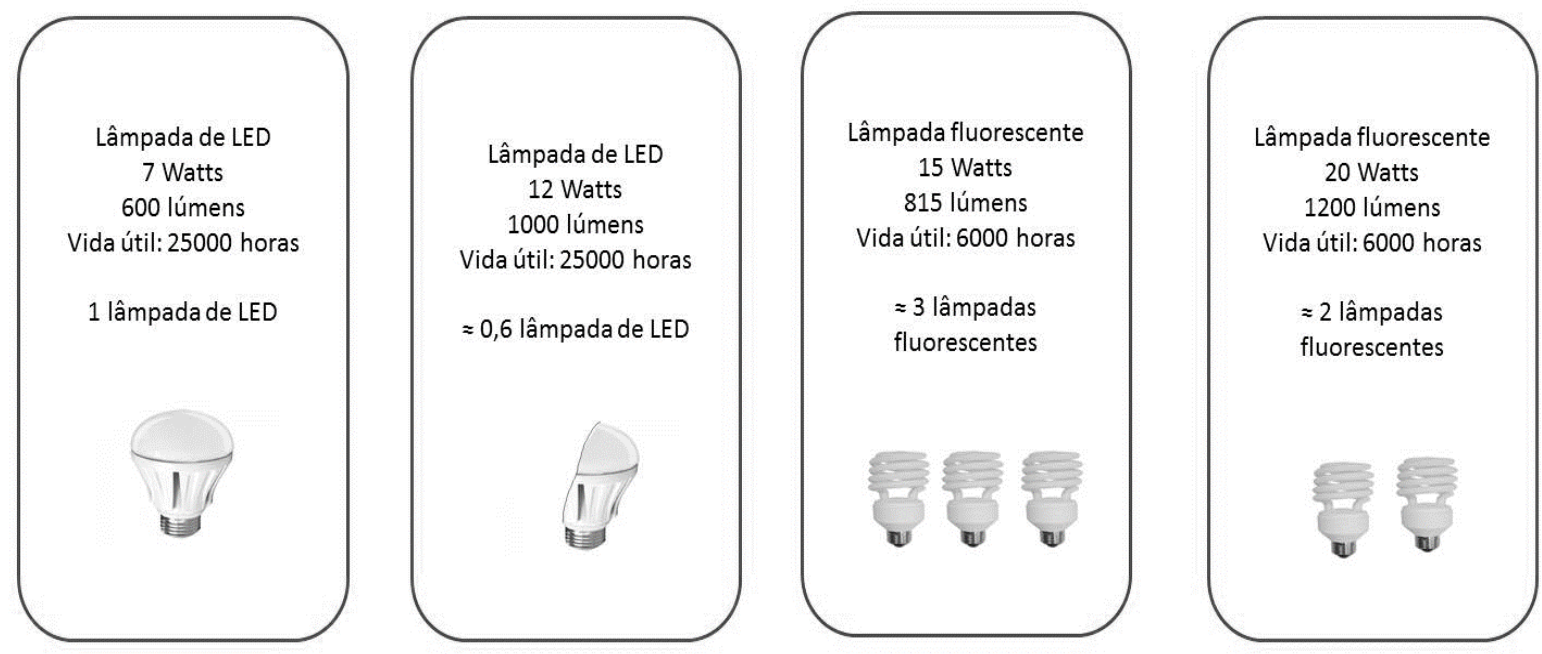

FIGURA 5: Número de lâmpadas necessárias para fornecer 15 milhões de lúmens-hora.

FONTE: Autoria Própria (2016). 


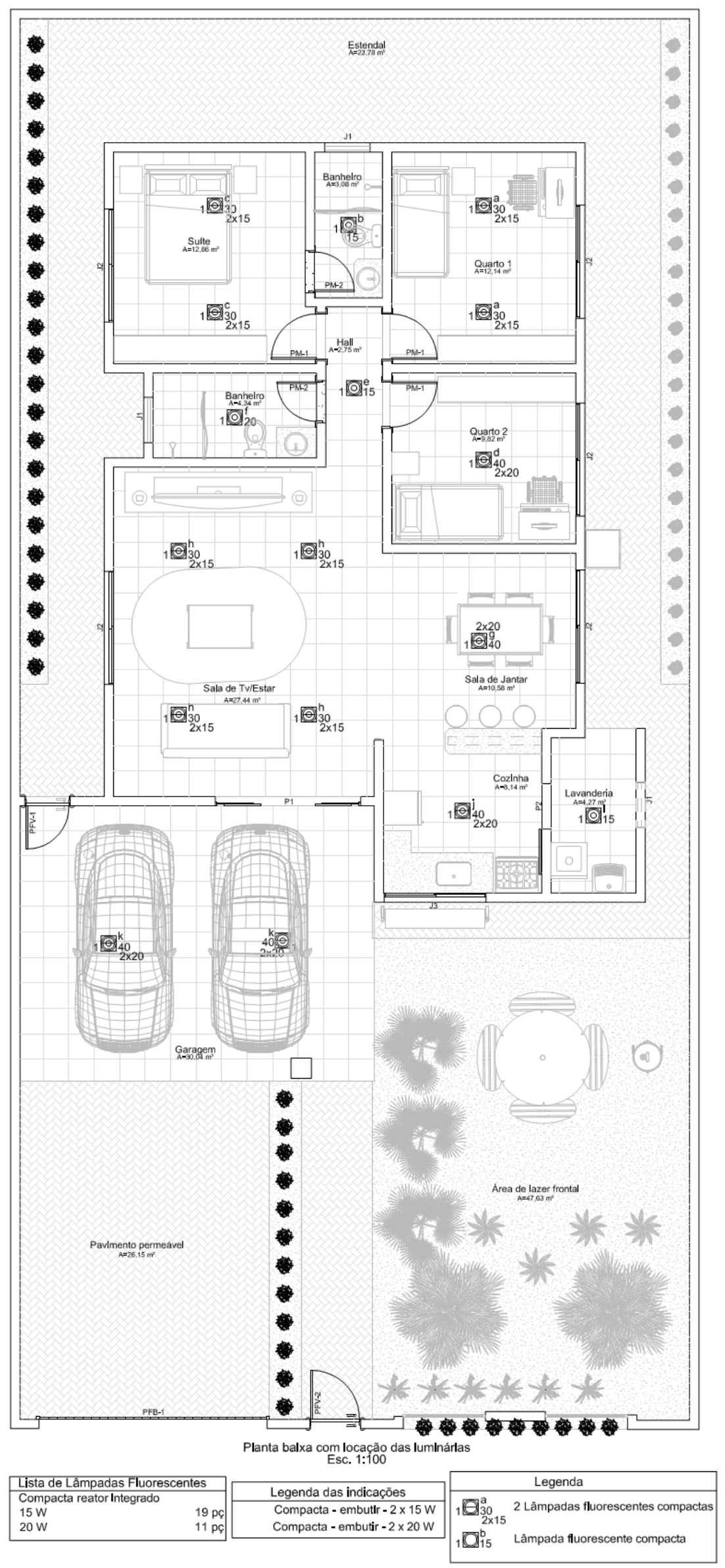

FIGURA 6: Planta baixa com locação das luminárias com lâmpadas fluorescentes. FONTE: Autoria Própria (2016). 

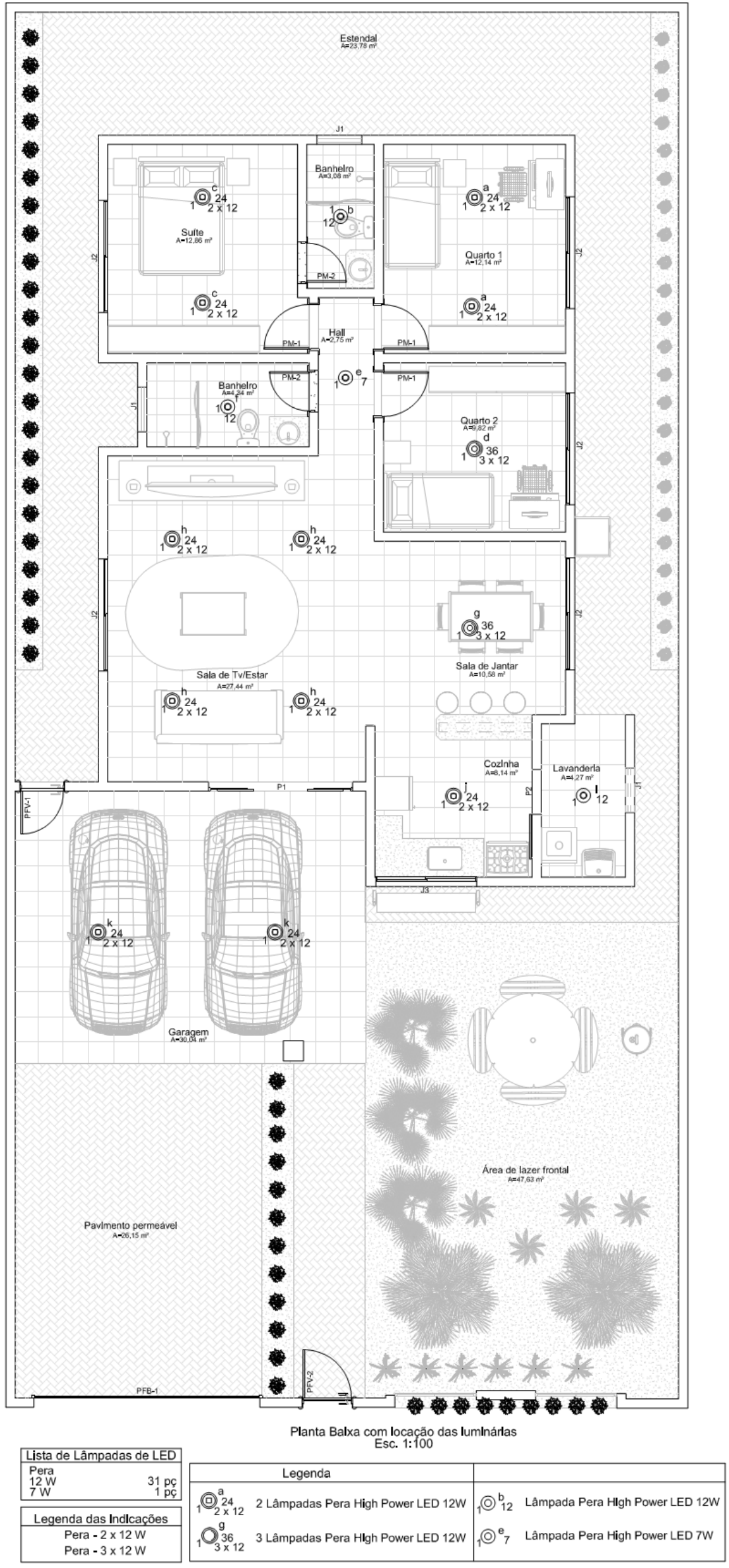

FIGURA 7: Planta baixa com locação das luminárias com lâmpadas de LED.

FONTE: Autoria Própria (2016). 
Considerando os preços apresentados no mercado de Catalão, para obter um mesmo iluminamento médio para a residência, obedecendo ao método dos lúmens, o tempo aproximado para pagar o investimento inicial das lâmpadas de LED em relação às fluorescentes é de 10500 horas. Feito uma suposição que essas lâmpadas ficam ligadas cerca de 5 horas por dia, conforme estimado pelo Centro Brasileiro de Informação de Eficiência Energética (PROCEL INFO, 2006) esse tempo equivale a menos de 6 anos, todavia, essa consideração é válida caso os preços se mantenham.

Comparando as lâmpadas de LED e fluorescentes em relação à vida útil (LED - 25000 horas), na Tabela 6 , são expostos o valor monetário e a emissão de $\mathrm{CO}_{2}$ para todas as lâmpadas fluorescentes e de LED necessárias ao projeto. As lâmpadas de LED apresentam vantagens em todos os sentidos, nesse período, tal que na Tabela 7 são apresentadas as reduções obtidas ao trocar todas as lâmpadas de LED pelas fluorescentes que atenderiam aproximadamente aos mesmos iluminamentos médios recomendados na NBR 5413 (ABNT, 1992).

Ressalta-se que no Brasil a matriz energética é baseada principalmente em hidroelétricas, e para as mesmas, a emissão de $\mathrm{CO}_{2}$ equivalente é igual a $41 \mathrm{~g} / \mathrm{kWh}$, considerando todo o ciclo de vida operacional das barragens (Evans; Strezov; Evans, 2009), valor este considerando para os cálculos da Tabela 6.

Avaliando-se a Tabela 7 verifica-se que após 25000 horas úteis, o preço de aquisição das lâmpadas de LED já se torna $16,87 \%$ inferior ao das fluorescentes. O percentual para redução de energia é de $24,95 \%$, o que atinge diretamente o meio ambiente de forma positiva por ter como consequência a redução de emissão de $\mathrm{CO}_{2}$ equivalente. Somando o custo de aquisição das lâmpadas e do consumo de energia, confere-se que após 25000 horas úteis a economia gerada por escolher as lâmpadas de LED é de aproximadamente $23,39 \%$.

O estudo do DOE (2012b), que apresentou as emissões equivalentes de $\mathrm{CO}_{2}$, mostrou que as lâmpadas fluorescentes emitiam uma média de 15,2 $\mathrm{kg} \mathrm{CO}_{2}$ eq $\left(10^{6} \mathrm{Imh}\right)^{-1}$, enquanto as de LED em 2012 emitiam uma média de $12,5 \mathrm{~kg} \mathrm{CO}_{2}$ eq $\left(10^{6} \mathrm{Imh}\right)^{-1}$, o que representa uma redução de quase $18 \%$. Ao considerar as diferenças entre os Estados Unidos e o Brasil, e ainda os três anos de intervalo entre um estudo e outro, ainda se percebe que a redução de quase $25 \%$ nas emissões no projeto da cidade de Catalão está pertinente em relação a outros estudos semelhantes.

Observou-se que as lâmpadas de LED utilizadas no mercado de Catalão apresentam um custo de aquisição inicial mais alto. Contudo, considerando-se que o preço dessas lâmpadas e da energia elétrica se mantenham, após um período de 25000 horas há uma economia de $23,39 \%$ e o custo inicial delas seria pago após aproximadamente 10500 horas, equivalente a menos de seis anos. Acredita-se que há uma tendência de redução no preço dessas lâmpadas, podendo diminuir ainda mais esse período. Considerando-se um estudo realizado em 2013 por Ferreira e Tomioka (2013), que verificou a economia potencial de energia elétrica através da iluminação de LED, percebe-se que o tempo de retorno de investimento teve uma redução, pois o trabalho desses autores chegou a um resultado de 16000 horas contra 10500 horas deste trabalho. Isso pode ser devido ao período de diferença entre os estudos e a tendência de redução no preço das lâmpadas de LED, tal como a evolução na tecnologia da sua produção, e também pode ser por se tratar de uma pesquisa em um mercado mais específico.

Em relação ao impacto ambiental, destaca-se que conforme analisado nos documentos do Departamento de Energia dos Estados Unidos (DOE), a etapa de uso das lâmpadas é a que mais contribui no consumo de energia. $E$ ao comparar as lâmpadas de LED e fluorescentes em Catalão, o consumo energético das primeiras é inferior, reduzindo diretamente as emissões de $\mathrm{CO}_{2}$, tal que após um período de 25000 horas, a redução já é quase de $25 \%$. 
TABELA 6: Valor monetário e emissão de $\mathrm{CO}_{2}$ das lâmpadas fluorescentes e de LED necessárias para o projeto de uma casa-piloto para Catalão.

\begin{tabular}{|c|c|c|c|c|c|c|c|c|c|c|c|}
\hline \multicolumn{6}{|c|}{ Lâmpada } & \multicolumn{3}{|c|}{ Valor monetário para adquirir as lâmpadas } & \multicolumn{2}{|c|}{$\begin{array}{l}\text { Valor monetário de } \\
\text { consumo de energia }\end{array}$} & \multirow{2}{*}{\begin{tabular}{|c|}
$\begin{array}{c}\text { Avaliação } \\
\text { ambiental }\end{array}$ \\
$\begin{array}{c}\text { Emissão de } \\
\mathrm{CO}_{2} \text { em } 25000 \\
\text { h }\left(\mathrm{kgCO}_{2 \text { eq }}\right)\end{array}$ \\
\end{tabular}} \\
\hline Tipo & Especificação & $\begin{array}{l}\text { Qtd. } \\
\text { (pç) }\end{array}$ & $\begin{array}{c}\text { Potência } \\
\text { nominal } \\
\text { (W) }\end{array}$ & $\begin{array}{l}\text { Vida } \\
\text { útil } \\
\text { média } \\
\text { (h) } \\
\end{array}$ & $\begin{array}{c}\text { Fluxo } \\
\text { luminoso } \\
\text { médio }(\mathrm{Im})\end{array}$ & $\begin{array}{l}\text { Preço Médio } \\
\text { Unitário } \\
\text { (R\$/unidade) }\end{array}$ & $\begin{array}{c}\text { Preço Médio } \\
\text { Total Inicial } \\
\text { (R\$) }\end{array}$ & $\begin{array}{l}\text { Preço médio } \\
\text { Total para } \\
25000 \text { h }(R \$)^{1}\end{array}$ & $\begin{array}{c}\text { Consumo } \\
\text { de energia } \\
\text { para } 25000 \\
\text { h (kWh) }\end{array}$ & $\begin{array}{l}\text { Custo total de } \\
\text { energia para } \\
25000 \text { h }(R \$)^{2}\end{array}$ & \\
\hline \multirow{3}{*}{ Fluorescente } & $\begin{array}{c}\text { Fluorescente } \\
15 \mathrm{w} \\
\end{array}$ & 19 & 15 & 6000 & 815 & $\mathrm{R} \$ 8,15$ & $\mathrm{R} \$ 154,85$ & $\mathrm{R} \$ 774,25$ & 7125 & $\mathrm{R} \$ 3.324,53$ & 292,13 \\
\hline & $\begin{array}{c}\text { Fluorescente } 20 \\
\text { W } \\
\end{array}$ & 11 & 20 & 6000 & 1200 & $\mathrm{R} \$ 11,50$ & $\mathrm{R} \$ 126,50$ & $\mathrm{R} \$ 632,50$ & 5500 & $R \$ 2.566,30$ & 225,50 \\
\hline & Total & 30 & - & - & - & - & $\mathrm{R} \$ 281,35$ & $\mathrm{R} \$ 1.406,75$ & 12625 & $\mathrm{R} \$ 5.890,83$ & 517,63 \\
\hline \multirow{3}{*}{ LED } & $\begin{array}{c}\text { Pera High } \\
\text { Power LED 7W }\end{array}$ & 1 & 7 & 25000 & 600 & $R \$ 22,50$ & $R \$ 22,50$ & $\mathrm{R} \$ 22,50$ & 175 & $\mathrm{R} \$ 81,66$ & 7,18 \\
\hline & $\begin{array}{c}\text { Pera } 12 \mathrm{~W} \\
\text { Bivolt } \\
\end{array}$ & 31 & 12 & 25000 & 1000 & $R \$ 37,00$ & $\mathrm{R} \$ 1.147,00$ & $\mathrm{R} \$ 1.147,00$ & 9300 & $\mathrm{R} \$ 4.339,38$ & 381,30 \\
\hline & Total & 32 & - & - & - & - & $\mathrm{R} \$ 1.169,50$ & $\mathrm{R} \$ 1.169,50$ & 9475 & $\mathrm{R} \$ 4.421,04$ & 388,48 \\
\hline
\end{tabular}

${ }^{1}$ Considera-se que são necessárias, aproximadamente, 4 lâmpadas fluorescentes para iluminar o mesmo tempo de vida de uma lâmpada de LED (25000 h)

${ }^{2}$ A tarifa de energia da CELG até 11/09/2016 é de 0,46660 R\$/kWh para classe de consumo residencial (ANEEL, 2016)

TABELA 7: Redução dos custos e emissões de $\mathrm{CO}_{2}$ com a substituição de lâmpadas fluorescentes por lâmpadas de LED considerando $25000 \mathrm{~h}$.

\begin{tabular}{|c|c|c|c|c|c|}
\hline Projeto & $\begin{array}{c}\text { Preço médio Total para aquisição } \\
\text { das lâmpadas (R\$) }\end{array}$ & $\begin{array}{l}\text { Consumo de } \\
\text { energia (kWh) }\end{array}$ & $\begin{array}{c}\text { Custo total de } \\
\text { energia (R\$) }\end{array}$ & $\begin{array}{l}\text { Custo de aquisição de lâmpadas e } \\
\text { consumo de energia (R\$) }\end{array}$ & $\begin{array}{c}\text { Emissão de } \mathrm{CO}_{2} \\
\left(\mathrm{kgCO}_{2 \text { eq }}\right)\end{array}$ \\
\hline Projeto com lâmpadas fluorescentes & $\mathrm{R} \$ 1.406,75$ & 12625 & $\mathrm{R} \$ 5.890,83$ & $\mathrm{R} \$ 7.297,58$ & 517,625 \\
\hline Projeto com lâmpadas de LED & $\mathrm{R} \$ 1.169,50$ & 9475 & $\mathrm{R} \$ 4.421,04$ & $\mathrm{R} \$ 5.590,54$ & 388,475 \\
\hline Redução (\%) & $16,87 \%$ & $24,95 \%$ & $24,95 \%$ & $23,39 \%$ & $24,95 \%$ \\
\hline
\end{tabular}


Através do estudo desenvolvido reconheceu-se que as lâmpadas de LED apresentam uma excelente alternativa, pois possuem maior vida útil, variedade de cores e tamanhos, consomem pouca energia, entre outras características. Ao se verificar a aplicação dessas lâmpadas e das fluorescentes no mercado de Catalão, constatou-se que, de fato, elas melhoram a eficiência energética por apresentarem redução de consumo, redução de impactos ambientais e redução de investimento e custos considerando-se uma vida útil de 25000 horas. Decorrendo poucos anos as lâmpadas de LED compensam o seu maior preço inicial e impactam diretamente na redução de emissão de $\mathrm{CO}_{2}$ devido ao menor consumo de energia.

É viável adotar lâmpadas de LED no lugar das fluorescentes. Esse resultado contraria o que Bley (2012) afirmou em seu estudo comparativo entre lâmpadas convencionais e de LED, em que ele alegou que o tempo de retorno era muito alto (podendo ultrapassar 100 anos) e inviabilizava essa substituição. Essa divergência entre os resultados pode indicar a rápida evolução das lâmpadas de LED, mostrando que em poucos anos, elas passaram a ter mais opções e estão cada vez mais acessíveis no mercado, obtendo maior viabilidade financeira.

\section{CONCLUSÕES}

Com a substituição das lâmpadas fluorescentes pelas de LED, considerando-se um projeto de uma edificação residencial unifamiliar para a cidade de Catalão deixa-se de emitir $129,15 \mathrm{~kg}$ de $\mathrm{CO}_{2 \text { eq }}$ (redução de 24,95\%) para a atmosfera no período de $25000 \mathrm{~h}$ de vida útil das lâmpadas. Há também uma redução de 23,39\% nos gastos com aquisição das lâmpadas e consumo de energia ( $R \$ 1.707,04)$, considerando-se o mesmo período de vida útil e os preços atuais de energia e das lâmpadas. Essa economia pode ser ainda maior considerando-se que as lâmpadas de LED estão reduzindo o preço com o passar dos anos e a energia está cada vez mais cara.

Logo, o estudo provou para o caso estudado, a viabilidade da troca das lâmpadas fluorescente pelas de LED, podendo auxiliar na conscientização das pessoas em relação à importância de adotar lâmpadas mais eficientes. Foi mostrado que essa substituição é uma ação simples que contribui na redução do impacto ambiental e ainda beneficia o usuário tanto no ponto de vista técnico quanto econômico.

\section{REFERÊNCIAS BIBLIOGRÁFICAS}

ABNT - ASSOSSIAÇÃO BRASILEIRA DE NORMAS TÉCNICAS. NBR 5413 - Iluminância de interiores. Rio de Janeiro, 1992.

ANEEL. Conheça as tarifas da classe de consumo residencial de uma concessionária. Disponível em: <http://www.aneel.gov.br/aplicacoes/tarifaAplicada/ind ex.cfm> Acesso em: 26 jan. 2016

ASSIS, E. S., PEREIRA, E. M. D., SOUZA, R. V. G., DINIZ, A. S. A. C. Habitação social e eficiência energética: um protótipo para o clima de Belo Horizonte. II Congresso Brasileiro de Eficiência Energética, 2007, Vitória, 1-7.

AUTODESK. AutoCad. Versão gratuita de avaliação. 2016 Disponível

em: <http://www.autodesk.com.br/products/autocad/freetrial>. Acesso em 14 dez. 2015.

AUTOQI. Lumine V4. Versão demonstrativa. 2015. Disponível em: <http://www.altoqi.com.br/download/lumine/v4/versa o-demonstrativa-v4>. Acesso em 14 dez. 2015.

AVANT. Catálogo: Lâmpada Bulbo A19 - Pera High Power LED. $2014 . \quad$ Disponível em: <http://www.avantled.com.br/2013/images/all/LED/Lin ha-LED/Pera-High-Power/LEDPERA-HIGH-POWER.pdf>. Acesso em: 04 dez. 2015.

BLEY, F. B. LEDs versus Lâmpadas Convencionais: Viabilizando a troca. Especialize - Revista Online, ed. 3, p. 1-24, 2012

BORGES, D. A. Princípios de eficiência energética para uma casa na cidade de Catalão - Goiás. 2016. 126 f. Trabalho de Conclusão de Curso (Graduação em Engenharia Civil) - Faculdade de Engenharia, Universidade Federal de Goiás / Regional Catalão. 2016.

BRASIL. Portaria Interministerial no 1.007, de 31 de dezembro de 2010. Dispõe sobre a produção e importação para fins de comercialização de lâmpadas incandescentes. Brasília, 2010. Disponível em: <http://www.mme.gov.br/documents/10584/904396/P ortaria_interminestral+1007+de+31-122010+Publicado+no+DOU+de+06-01-2011/d94edaad5e85-45de-b002-f3ebe91d51d1?version=1.1>. Acesso em 04 dez. 2015. 
COPEL - COMPANHIA PARANAENSE DE ENERGIA. Uso eficiente de energia na sua casa. 2011. Disponível em: <http://www.copel.com/hpcopel/root/nivel2.jsp?ender eco $=\% 2 \mathrm{Fhp}$

copel\%2Froot\%2Fpagcopel2.nsf\%2F0\%2F9C83B5131AF5 4B1B032573EC005D8B0D> Acesso em 30 nov. 2015.

CREDER, H. Instalações elétricas. 15 ed. Rio de Janeiro: LTC, 2007. 914 p.

DOE - U.S. DEPARTMENT OF ENERGY. Life-Cycle assessment of energy and environmental impacts of LED lighting products - Part I: Review of the life-cycle energy consumption of incandescent, compact fluorescent, and LED lamps. Washington, 2012.46 p. Disponível em: <http://apps1.eere.energy.gov/buildings/publications/p dfs/ssl/2012_LED_Lifecycle_Report.pdf $>$. Acesso em: 30 nov. 2015.

EPE - EMPRESA DE PESQUISA ENERGÉTICA. Anuário Estatístico de Energia Eletrica 2015 - ano base 2014. 2015. Disponível em: <https://ben.epe.gov.br/BENRelatorio Sintese. aspx ?anoColeta=2015\&anoFimColeta $=2014>$ Acesso em: 30 nov. 2015

EVANS, A.; STREZOV, V.; EVANS, T. J. Assessment of sustainability indicators for renewable energy technologies. Renewable and sustainable energy rewies, v. 13, p. 1082-1088, 2009.

FERREIRA, A. R. Iluminação do estado sólido, economia potencial de energia elétrica para o país. 2014. 96 f. Dissertação (Mestrado em Engenharia Elétrica) - Curso de Pós-Graduação, Universidade Federal do ABC, Santo André, 2014.

FERREIRA, A. R.; TOMIOKA, J. Iluminação do estado sólido, economia potencial de energia elétrica para o país. In: VIII WORKSHOP DE PÓSGRADUAÇÃO E PESQUISA DO CENTRO PAULA SOUZA Sistemas produtivos: da inovação à sustentabilidade, 8, 2013, São Paulo. Anais... São Paulo: Centro Paula Souza Governo do Estado de São Paulo, 2013, p. 313-323.

FREITAS, P. C. F. Lâmpadas elétricas e luminotécnica. Uberlândia: UFU, 2009. Apostila.

FIASCHI, D.; BANDINELLI, R.; CONTI, S. A case study for energy issues of public building and utilities in a small municipality: Investigation of possible improvements and integration with renewables. Applied Energy, v. 97, p. 101-114, 2012.

INMETRO - INSTITUTO NACIONAL DE METROLOGIA, QUALIDADE

TECNOLOGIA. Informação ao consumidor: Etiquetas. $2012 . \quad$ Disponível em: <http://www.inmetro.gov.br/consumidor/etiquetas.asp >. Acesso em: 30 nov. 2015
KAWASAKI, J. I. Métodos de cálculo luminotécnico. Revista: O Setor Elétrico, ed. 74, p. 36-42, 2012.

LAMBERTS, R.; DUTRA, L.; PEREIRA, F. O. R. Eficiência energética na arquitetura. 3 ed. Rio de Janeiro: Eletrobrás PROCEL, 2014, 366 p. Disponível gratuitamente em: <http://www.mme.gov.br/documents/10584/1985241/ Livro\%20-\%20Efici\%C3\%AAncia\%20

Energ\%C3\%A9tica\%20na\%20Arquitetura.pdf>. Acesso em: 15 jun. 2015.

LAMBERTS, R.; TRIANA, M. A. Levantamento do estado da arte: Energia. Documento 2.2. Projeto Tecnologias para construção habitacional mais sustentável. São Paulo: FINEP, 2007. 94 p.

LEELAKULTHANIT, O. The factors affecting the adoption of LED Lamps. International Business \& Economics Research Journal, v. 13, n. 4, p. 757-768, 2014.

OLIVEIRA, A. F., JORDÃO R. V., RESENDE, R. B., CAPUTO, R. C., SILVA, R. C. Projeto de residência com melhor aproveitamento energético. Revista: O Setor Elétrico, ed. 109, p. 70-81 , 2015. Disponível em: http://www.osetoreletrico.com.br/web /a-revista/1608projeto-de-residencia-com-melhor-aproveitamentoenergetico. html. (Acesso em: 21 jan. 2016).

OSRAM. Manual luminotécnico prático. [2001] Disponível em: <http://www.iar.unicamp.br/lab/luz/ld/Livros/ManualO sram.pdf>. Acesso em: 03 dez. 2015

PHILIPS. Technical data. 2010. Disponível em: <http://www.ribaproductselector.com/

Docs/9/05799/external/COL2205799.pdf> Acesso em: 03 dez. 2015

PROCEL INFO - CENTRO BRASILEIRO DE INFORMAÇÃO DE EFICIÊNCIA ENERGÉTICA. Dicas de economia de energia. 2006. Disponível em <http://www.procelinfo.com.br/main.asp?View=\%7BE6 BC2A5F-E787-48AF-B485-439862B17000\%7D> (Acesso em: 29 jan. 2016).

SANTOS, A. S. Análise inversa aplicada no dimensionamento de iluminação artificial em ambientes. 2010. 91 p. Dissertação (Mestrado em Engenharia) - Programa de Pós-Graduação em Engenharia Mecânica, Escola de Engenharia, Universidade Federal do Rio Grande do Sul, Porto Alegre, 2010.

TOLEDO, B. G. Integração de iluminação natural e artificial: Métodos e guia prático para projeto luminotécnico. 2008. 165 p. Dissertação (Mestrado em Arquitetura e Urbanismo) - Programa de Pós-Graduação em Arquitetura e Urbanismo da Faculdade de Arquitetura e Urbanismo, Universidade de Brasília, Brasília, 2008. 
UDDIN, S.; SHAREEF, H.; MOHAMED, A. Power quality performance of energy-efficient low-wattage LED lamps.Measurement, v. 46, n. 10, p. 3783-3795, 2013 